\title{
A Multidisciplinary Evaluation of Patients with DMD in An Italian Tertiary Care Center
}

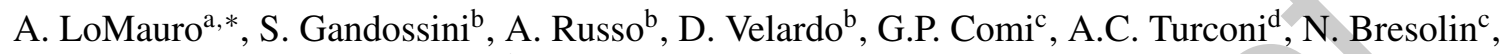 \\ A. Aliverti ${ }^{\mathrm{a}}$ and M.G. D’Angelo ${ }^{\mathrm{b}}$ \\ ${ }^{a}$ Dipartimento di Elettronica, Informazione e Bioingegneria, Politecnico di Milano, Milano, Italy \\ ${ }^{\mathrm{b}}$ Scientific Institute IRCCS E. Medea, Neuromuscular Unit, Bosisio Parini (Lecco) Italy \\ ${ }^{\mathrm{c}}$ Dino Ferrari Centre, Neuroscience Section, Department of Pathophysiology and Transplantation (DEPT), \\ Neurology Unit, IRCCS Foundation Ca' Granda Ospedale Maggiore Policlinico, University of Milan \\ ${ }^{\mathrm{d}}$ Scientific Institute, IRCCS E. Medea-via don Luigi Monza, Bosisio P (Lecco) Italy
}

\begin{abstract}
With more widespread prolonged survival, Duchenne muscular dystrophy patients progressively experience multisystem complications. We retrospectively reviewed the charts of 132 Duchenne patients (112 alive/20 dead, age $3.5 \div 32.3$ years) with the aims: 1) to provide a comprehensive description of the clinical status considering different aspects of the disease; 2) to propose a new scoring tool able to consider and pool together heterogeneous different functional. Five functions were analyzed: cardiac, respiratory, nutritional, ambulation and scoliosis. For each function, different items were considered and classified according to clinical severity (as indicated by international guidelines) and an incremental scoring was assigned. In addition, a global score incorporating all functions was defined. The scoring system confirmed that despite the significant protective role of steroids, all functions deteriorated with age. The severity of the global score became significantly higher since the age of 13 years. The severity of cardiac, respiratory and nutritional dysfunction was higher since 18 years. Deceased patients were characterized by significantly worse cardiac function, absence of steroid therapy and later use of respiratory assistive devices. The index proposed in this pilot study is a promising tool able to aggregate and correlate heterogeneous functions. It could become either an individual prognostic indicator of decline or a global score to evaluate changes in clinical trials therefore allowing multicenter studies, optimizing the management of both the primary and the secondary complications of the disease and understanding their relative impact.
\end{abstract}

Keywords: Duchenne muscular dystrophy, natural history, respiratory function, cardiac function, nutrition, indexes

\begin{tabular}{|c|c|c|c|}
\hline \multicolumn{2}{|c|}{ ABBREVIATION } & CAD & Cough Assist Device \\
\hline \multirow{4}{*}{$\begin{array}{l}\text { ANOVA } \\
\text { AV } \\
\text { BEVS } \\
\text { BMI }\end{array}$} & \multirow{4}{*}{$\begin{array}{l}\text { Analysis of Variance } \\
\text { Ventricular Arrythmias } \\
\text { SovraVentricular Extrasistolia } \\
\text { Body mass index }\end{array}$} & $\mathrm{AF}$ & Atrial flutter/Fibrillation \\
\hline & & FVC\%pred & Forced vital capacity \\
\hline & & & percentage of predicted values \\
\hline & & ICD & $\begin{array}{l}\text { Implantable cardioverter- } \\
\text { defibrillator }\end{array}$ \\
\hline $\begin{array}{l}{ }^{*} \text { Corresp } \\
\text { Elettronica, } \\
\text { Piazza Leo } \\
\text { nella.lomau }\end{array}$ & $\begin{array}{l}\text { e to: Antonella LoMauro, Dipartimento di } \\
\text { azione e Bioingegneria, Politecnico di Milano, } \\
\text { da Vinci, } 20133 \text { Milano Italy. E-mail: anto } \\
\text { limi.it. }\end{array}$ & $\begin{array}{l}\text { LVEF } \\
\text { MNIV }\end{array}$ & $\begin{array}{l}\text { Left ventricular ejection fraction } \\
\text { Mechanical Non Invasive } \\
\text { Ventilation } \\
\text { Sinus Tachycardia }\end{array}$ \\
\hline
\end{tabular}




\section{INTRODUCTION}

Duchenne muscular dystrophy (DMD) is an Xlinked recessive disorder, characterized by progressive muscle degeneration and weakness, caused by absence of the cell membrane protein called dystrophin. DMD mainly affects males with signs and symptoms onset usually between ages 3 and 5 years $[1,2]$.

Steroids and advances in cardiorespiratory care, led to increase life expectancy into the late 20 s for patients using ventilatory support and to approximately 40 years for patients using continuous noninvasive ventilatory support [3-7]. This prolonged survival of DMD patients results into additional disease complications, such as malnutrition, impaired swallowing, scoliosis, steroid side effects, daily living, quality of life, employment, social engagement. They need early identification and treatment; therefore creating a significant challenge in managing a multidisciplinary clinical approach and in designing new scales and/or scores that account for the different aspects of the disease, in order to provide a new tool able to follow the disease progression. At present, only two studies have analyzed these multi-systemic complications in a wide DMD population $[8,9]$; whereas all the other published studies deal with only one aspect of the disease, probably due to the difficulty to consider all the heterogeneous functions and parameters that characterize DMD. For this reason, we retrospectively reviewed the charts of all the DMD subjects followed at the Scientific Institute E. Medea, an Italian tertiary care center where patients are monitored from childhood to adulthood by a multidisciplinary team, with two aims: 1) to describe the clinical status of DMD boys taking into account different items: ambulation, steroid therapy, scoliosis, cardiac and respiratory function, swallowing and nutrition and 2) to propose a new scoring tool able to pool together heterogeneous different functional parameters for each considered function. The multidisciplinary description of the clinical condition of our population would represent precious natural history data to evaluate the possible impact on different aspects of the disease of new treatments and therapies. The proposed scoring system, created according to clinical guidelines [7, 10, 11], could be a new tool able to: a) follow the evolution of the clinical status in DMD; b) be a potential benchmarking between national and international specialized centers for the treatment of DMD; c) define what complication/s play the most relevant role in the disease history and their possible interaction; d) compare dead and alive patients in terms of the defined indexes.

A scoring system of this type might have the potentiality to be applied in daily clinical practice, as a potential indicator of treatment start, and in clinical trial settings, as severity scale for inclusion criteria or for patients' stratification.

\section{MATERIALS AND METHODS}

\section{Patients}

We retrospectively reviewed the charts of all the patients with a diagnosis of Duchenne Muscular Dystrophy followed at the E. Medea Institute.

Patients not responding to international criteria for the diagnosis of DMD [10], the ones who died before 2000 and the ones recruited in clinical trials (i.e., gene-modulating and deacetilase inhibitors studies) were excluded from our analysis. Therefore, only DMD patients with a certain diagnosis and regular records with neuromuscular and motor function evaluation, cardiac and respiratory, nutritional and swallowing evaluations, orthopedic and X-ray assessments were included in the study.

The data collected and presented of both alive and dead boys are referred to the most recent clinic visit. The reported data of dead patients were collected less than 6 months before death.

Informed consent for clinical data collection from the neuromuscular database, approved by the Institutional review board, was obtained by patients and parents/legal tutors.

\section{Data collection}

Genotype (deletion, duplication or point mutation in the DMD gene), age at last evaluation, ambulation (if present), age at loss of ambulation, details about the use of steroid, in terms of age at which treatment started and/or stopped (when applicable) were collected for each boy.

According to steroid therapy patients were classified in naive (never treated or treated for $<1$ year), past (not under treatment, but previously treated for $>1$ year), current (under treatment or stopped since $<1$ year before the visit).

According to the age at last evaluation, patients were divided in: $\leq 5$ years (pre-symptomatic or early ambulatory stage), 6-9 (ambulatory stage), 10-12 years (late ambulatory stage), 13-17 years (early non 
ambulatory stage), 18-23 years (late non ambulatory stage), $\geq 24$ years (advanced stage) [12].

The indications for pharmacological therapy, use of devices, and in general the orthopaedic, respiratory, cardiac and nutritional management of the patients were performed according to the international guidelines specific for DMD [7, 10, 13].

\section{Index definition}

Five functions were considered at last observation: ambulation, range of scoliosis, cardiac function, respiratory function and nutrition. For each function, different functional items were considered. Each item was classified according to its clinical severity and an incremental scoring was assigned as described below and summarized in Table 1. In detail:

1. Ambulation. If the patient was wheelchair bound, this function was assigned score 1. If the patient was ambulant, score 0 .

2. Range of scoliosis. It was evaluated by Cobb angle measurement on X-ray and classified as: absence of scoliosis (score 0), mild scoliosis (Cobb angle $<20^{\circ}$, score 1 ) moderate (Cobb angle $20-40^{\circ}$, score 2$)$, severe $\left(>40^{\circ}\right.$, score 3$)$ and spinal fusion (score 4) [14];

3. Cardiac function. It was evaluated through echocardiography, 24 hours electrocardiographic recording and electrocardiogram. Two functional parameters were considered to score the cardiac function: left ventricular ejection fraction (LVEF) and cardiac rhythm. The function of LVEF was considered normal when $\geq 60 \%$ (score 0 ), initial dysfunction when $\geq 50$ and $<60 \%$ (score 1 ), mild dysfunction when $\geq 40$ and $<50 \%$ (score 2 ), moderate-severe dysfunction when $<40 \%$ (score 3) [15]. Cardiac rhythm analysis were classified as: Sinus Tachycardia (score 1); SovraVentricular Extrasystolia (score 2); Ventricular Arrythmias (score 3); sustained Atrial flutter/Fibrillation (AF, score 4). The absence of arrhythmia was scored 0 , while the presence of the implantable cardioverter-defibrillator (ICD) was given score 5 [16].

4. Respiratory function. It was evaluated through spirometry and subdivisions of lung volume by the nitrogen washout technique (Vmax series 22, SensorMedics, Yorba Linda, CA) at last evaluation. Among these, forced vital capacity expressed as percentage of predicted values (FVC\% pred) was considered and scored together with other two functional items: the effective use (and not the indication) of Cough Assist Device (CAD) and/or Mechanical Non Invasive Ventilation (MNIV). According to FVC\%pred, three groups were defined: patients with $\mathrm{FVC} \%$ pred $>$ $50 \%$ (score 0), with FVC\% $\%$ pred $\geq 30$ and $<50 \%$ (score 1); and FVC\%pred $<30 \%$ (score 2) [17]. If CAD and/or MNIV were currently used, each of them received a score of 1 , otherwise the score was 0 . The age at start of both CAD and MNIV were also recorded. The indication for the use of both respiratory devices was based on the international guidelines for respiratory care in dystrophic patients $[7,13]$.

5. Nutrition. It considered both the swallowing capabilities and the nutritional condition (obesity or pathological thinness). Based on anthropometric measures and body mass index (BMI) in accordance with a report of a WHO Consultation, patients were classified as normal weight (BMI ranging from 18.50 to $24.99 \mathrm{~kg}^{*} \mathrm{~m}^{2}$ ), pre-obese (BMI ranging from 25.00 to $29.99 \mathrm{~kg}^{*} \mathrm{~m}^{2}$ ), obese $\left(\mathrm{BMI}>30 \mathrm{~kg}^{*} \mathrm{~m}^{2}\right)$, pathological thinness (BMI $<18.5 \mathrm{Kg}^{*} \mathrm{~m}^{2}$ ) for adult patients [18-20]. For children (i.e. patients younger than 20 years old), the BMI z-score was calculated in relation to age and sex and interpreted through the use based on the Center for Disease Control growth charts [21]. Children were classified overweight if BMI $\mathrm{z}$-score $>+1 \mathrm{SD}$, obese if BMI $\mathrm{z}$-score $>+2 \mathrm{SD}$ and pathologically thin if BMI $z$-score $<-2$ sd. The presence of altered nutritional condition (obesity or pathological thinness) was scored 1, otherwise the score was 0 . Swallowing was evaluated in dedicated sessions with a speech and language therapist. According to food texture preparation, swallowing was classified as regular (all food, requiring regular chewing, score 0 ), mild dysphagia (soft food, requiring more chewing, score 1), moderate dysphagia (mechanically altered food, requiring some chewing, score 2), severe dysphagia (purees requiring no chewing, score 3) [2225]. The presence of percutaneous endoscopic gastrostomy was scored 4. Age at placement of percutaneous gastrostomy (when present) was also reported.

Because the range of the scores varied among the different considered items, they were all normalized to a range of $0-1$ by dividing each score by its maximal value (e.g.: FVC\% \%red score was divided by 2 , scoliosis by 4$)$. 
Table 1

Scoring system: criteria to assign each score to all the items of the considered functions

\begin{tabular}{|c|c|c|c|c|}
\hline Function & Item & level & score & $\overline{\text { N_score }}$ \\
\hline \multirow[t]{2}{*}{ ambulation } & wheelchair & no use & 0 & 0 \\
\hline & & use & 1 & 1 \\
\hline \multirow[t]{5}{*}{ scoliosis } & Cobb angle & $\operatorname{null}\left(0^{\circ}\right)$ & 0 & 0 \\
\hline & & mild $\left(<20^{\circ}\right)$ & 1 & 0.25 \\
\hline & & moderate $\left(20^{\circ}-40^{\circ}\right)$ & 2 & 0.5 \\
\hline & & severe $\left(>40^{\circ}\right)$ & 3 & 0.75 \\
\hline & & spinal fusion & 4 & 1 \\
\hline \multirow[t]{10}{*}{ cardiac } & LVEF & normal $(\geq 60 \%)$ & 0 & 0 \\
\hline & & initial dysfunction ( $\geq 50$ and $<60 \%$ ) & 1 & 0.33 \\
\hline & & mild dysfunction $(\geq 40$ and $<50 \%)$ & 2 & 0.67 \\
\hline & & moderate-severe dysfunction $(<40 \%)$ & 3 & 1 \\
\hline & cardiac rhythm & absence of arrhythmia & 0 & 0 \\
\hline & & Sinus Tachycardia & 1 & 0.20 \\
\hline & & SovraVentricular Extrasystolia & 2 & 0.40 \\
\hline & & Ventricular Arrythmias & 3 & 0.60 \\
\hline & & sustained Atrial flutter/Fibrillation & 4 & 0.80 \\
\hline & & $\mathrm{ICD}$ & 5 & 1 \\
\hline \multirow[t]{7}{*}{ respiratory } & FVC & $>50 \%$ & 0 & 0 \\
\hline & & $\geq 30$ and $<50 \%$ & 1 & 0.5 \\
\hline & & $<30 \%$ & 2 & 1 \\
\hline & CAD & no use & 0 & 0 \\
\hline & & use & 1 & 1 \\
\hline & MNIV & no use & 0 & 0 \\
\hline & & use & 1 & 1 \\
\hline \multirow{7}{*}{$\begin{array}{l}\text { gastrointestinal } \\
\text { and nutritional }\end{array}$} & nutritional & normal & 0 & 0 \\
\hline & condition & obesity or pathological thinness & 1 & 1 \\
\hline & Swallowing & regular & 0 & 0 \\
\hline & & mild dysphagia & 1 & 0.25 \\
\hline & & moderate dysphagia & 2 & 0.50 \\
\hline & & severe dysphagia & 3 & 0.75 \\
\hline & & PEG & 4 & 1 \\
\hline
\end{tabular}

N_score: normalized score to a range of $0-1$ by dividing the original score by its maximal value; LVEF: left ventricle ejection fraction; ICD: implantable cardioverter-defibrillator; FVC\% pred: forced vital capacity expressed as percentage of the predicted values; CAD: cough assisted device; MNIV: mechanical non-invasive ventilation; PEG: percutaneous endoscopic gastrostomy.

Each function was given a score obtained as the mean of the normalized scores of all the itmes considered for it. Each item was therefore attributed the same weight for the final score of the function.

A global final index was defined as the resulting mean of the scores of the five functions. Each function therefore equally contributed to the global final index.

The normalized scores of each item, the score of each function and the global index thus ranged from 0 (less severe) to 1 (most severe).

\section{Statistical analysis}

The age of patients and the age of ambulatory loss according to steroid therapy was tested by one-way non-parametric Kruskall-Wallis Analysis of Variance (ANOVA) with steroid use as independent factor. Similarly, the effect of age on the different indexes of alive patients was tested with age as independent factor. To investigate if the indexes differed between dead or alive patients, between naive, past and current steroids treated patients or between patients with deletion, duplication or point mutation in the DMD gene, three separate one-way non-parametric Kruskall-Wallis ANOVA were performed with death, steroid intake or genetic analysis as independent factor. Post-hoc tests were based on Dunn's method (SigmaStat 3.5, Systat Software, Inc, CaliforniaUSA). In the comparison with dead patients, only alive patients older than 13 years old were considered to match the age of both groups. Significance was determined by $p<0.05$. In the text, data are presented as median (range).

\section{RESULTS}

A total of 221 boys with Duchenne muscular dystrophy have attended the center since the '90s. 
Following inclusion and exclusion criteria, 132 boys with DMD evaluated from 2000 to 2017 were included in the study; 20 out of them died during this time span.

The results section was divided in three parts: 1) incidence of each considered function and item as a function of age in the alive DMD patients; 2) incidence of each considered function and item as a function of age in the DMD boys who deceased between 2000 and 2017; and 3) analysis of all the considered functions and items in terms of the proposed index as a function of age.

\section{DMD population: Alive patients}

One-hundred twelve subjects with a median age of 15.92 years (range 3.5-32.3) were included in the analysis and grouped according to age as follows: $\leq 5$ years $(n=5)$; 6-9 $(n=20) ; 10-12(n=15), 13-17$ $(n=30), 18-23(n=23), \geq 24(n=19)$.

Seventy-one were presenting deletions in the DMD gene; 26 point mutations and 15 duplications.

\section{Ambulation}

The median age at loss of ambulation was 10 (range 6.7-17.4) years; only 4 boys were ambulant above the age of 13 (the oldest being 16 years old) at last clinic visit (Fig. 1). The latest age of ambulation loss was 17.6 years.

\section{Steroid therapy}

41 patients identified as "current" were receiving steroids (deflazacort $0.9 \mathrm{mg} / \mathrm{kg}$ per day). The median age at start of therapy was 6 years. Most patients in ambulatory phase were treated with steroids: $60 \%$ in $\leq 5$ years group and $95 \%$ in $6-9$ years group. After loss of ambulation, the number of treated patients progressively decreased. The majority of patients older than 18 years (43\% in the 18-23 age group and $74 \%$ were older than 24 years) never used steroids while only 2 of them were still under treatment (Fig. 1). "Past" patients stopped the treatment at the median age of 12 (range $8-15$ ) years. None of these patients was ambulant at the study time. Patients under current steroid therapy were younger than past and naive $(p<0.005)$, while the age at loss of ambulation was similar $(p=0.482)$ among the three considered groups.

\section{Scoliosis}

Severity of scoliosis progressively increased with age (Fig. 1). Fourteen patients (12.5\% of overall population) underwent spinal fusion at the median age of 13.75 years.

\section{Cardiac function}

LVEF was found $>60 \%$ in the majority of children younger than 10 years except one whose LVEF was $<50 \%$. LVEF was $>50 \%$ in the majority of alive patients older than 18 years $(66 \%$ in the $18-23$ age group and 53\% were older than 24 years). Only 3 of them presented AF and 3 had ICD (Fig. 2). All patients with $\mathrm{LVEF}<50 \%$ were treated with beta blockers or angiotensin converting enzyme inhibitors or both, starting at a median age of 16.3 years. ICD were implanted after patient being on maximally tolerated guideline-directed medical therapy [26].
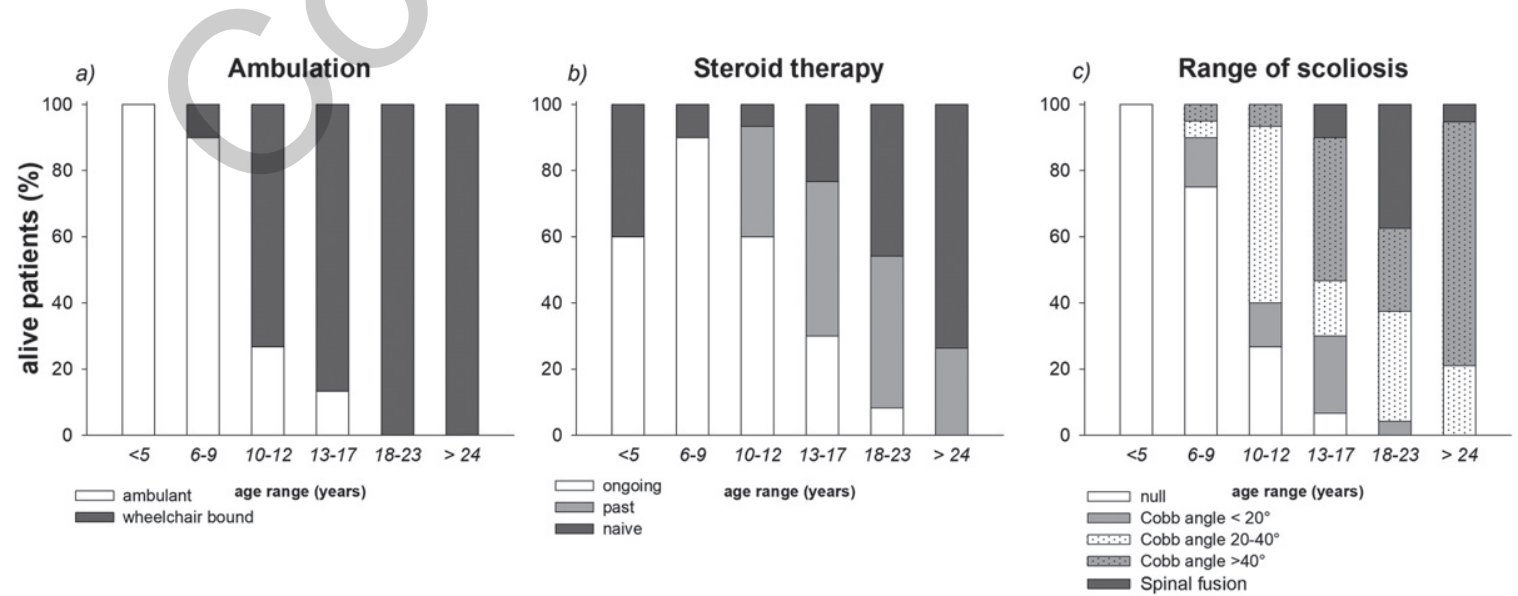

Fig. 1. Stacked diagrams of the different levels of ambulation, steroid therapy and scoliosis in the alive patients. Data are expressed as percentage of the numerosity of each group of age. 

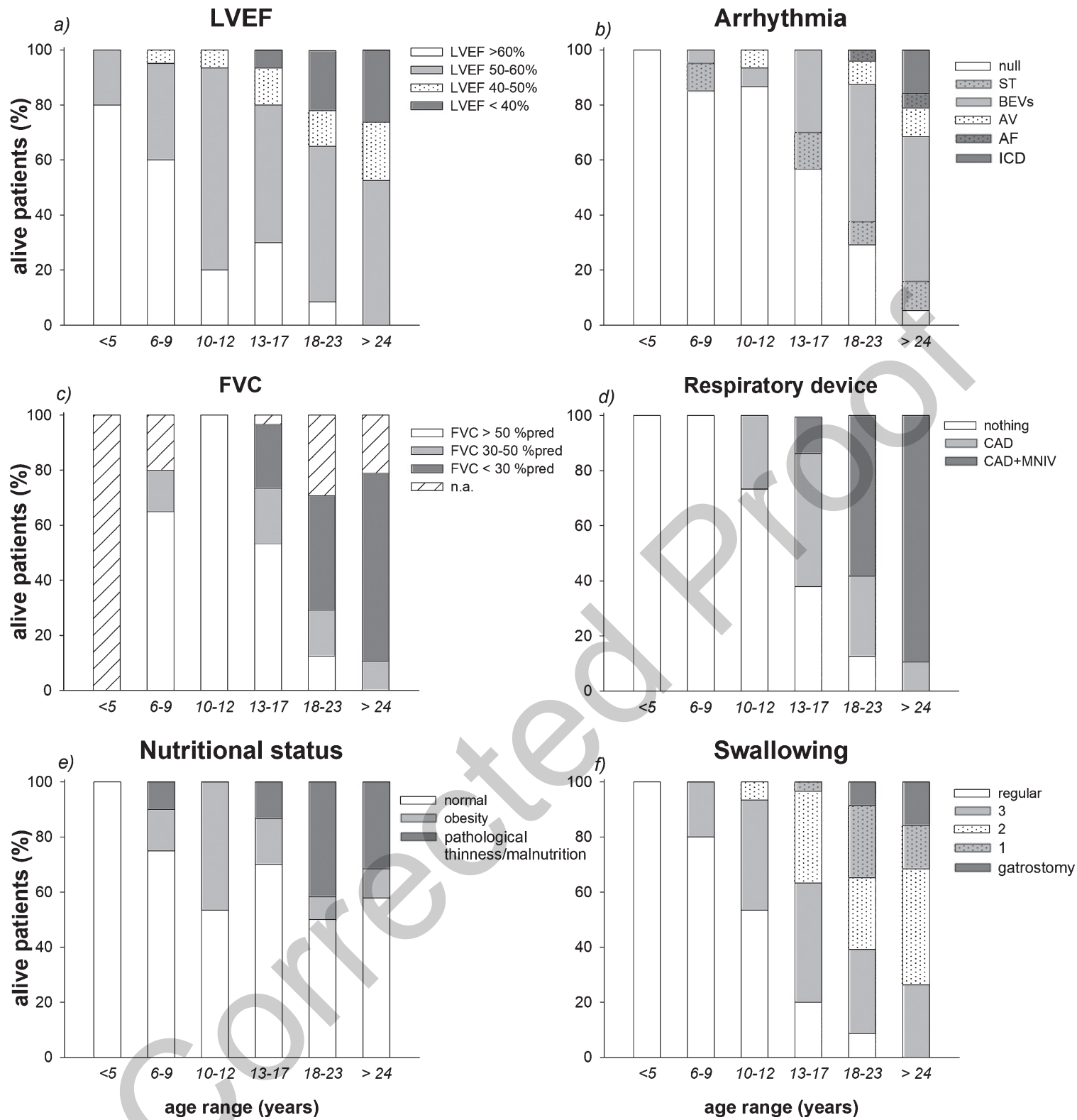

Fig. 2. Stacked diagrams of the different levels of left ventricular ejection fraction (LVEF), arrhythmia, forced vital capacity (FVC), respiratory device use, nutritional condition and swallowing disturbances in the alive patients. Data are expressed as percentage of the numerosity of each group of age. AV: Ventricular Arrythmias; BEVs: SovraVentricular Extrasistolia; AF: Atrial flutter/Fibrillation; TS: Sinus Tachycardia; ICD: implantable cardioverter-defibrillator; CAD: cough assisted device; MNIV: mechanical non-invasive ventilation.

\section{Respiratory function}

No reliable spirometric data were available in patients younger than 5 years. The numbers of pulmonary function tests decreased after the age of 18 years. The percentage of subjects with $\mathrm{FVC} \%$ pred $>50 \%$ predicted was $70 \%$ at the age of 6 years, it increased to $94 \%$ at 12 years to decline between 13 and 23 years (53\%) till disappearing after the age of 24 years (Fig. 2).

\section{Respiratory devices}

Patients started regular use of CAD at the age of 16 (10-31 years), and of MNIV at the age of 20 (15-34 years), reaching $100 \%$ and $95 \%$ of patients older than 
24 years (Fig. 2), respectively. None of our patients had tracheostomy or needed continuous noninvasive ventilatory support.

\section{Nutritional condition}

Obesity was observed in 19 patients. Fifteen were younger than 18 years $(15 \%$ in the $6-9$ age group, $46.7 \%$ in the $10-12$ age group and $16.7 \%$ in the $13-17$ age group.), while median BMI was $31.1 \mathrm{~kg}^{*} \mathrm{~m}^{2}$ in the remaining 4 adult patients. Nine obese patients belonged to the "current", 7 to the "past" and 3 to the "naïve" steroid group. The percentage of DMD boys presenting pathological thinness increased with age, 16 out of the 22 pathologically thin patients were older than 18 years with a median BMI of $14 \mathrm{~kg} \bullet \mathrm{m}^{2}$ (Fig. 2).

\section{Swallowing}

The percentage of patients and the severity of swallowing disturbances were directly correlated with age. Five patients positioned a gastrostomy at the median age of 29 (17-31) years (Fig. 2).

\section{DMD population: Dead (deceased) patients}

Although 20 boys died between 2000 and 2017, we considered only the 16 whose complete clinical evaluation was available within 6 months before death. No traumatic death occurred.

Median age at death was 19 (13.2-27) years. The two youngest died respectively at 13.9 and 13.2 years while still ambulant. The remaining 14 patients, lost ambulation at the age of 10.5 (8-12.6) years (Fig. 3). Eleven boys were carrying deletions, 2 point mutations and 3 duplications in the DMD gene. Most of these patients were steroid naive with severe scoliosis or spinal fusion, they had decreased LVEF and severe arrhythmias (AF was recorded in 2 subjects at 15 and 26 years), FVC\% $\%$ pred $<50 \%$ ( 3 patients were not able a reproduce a reliable spirometry), with pathological thinness (median BMI in 6 adult patients: $17 \mathrm{~kg}^{*} \mathrm{~m}^{2}$, while the 3 children were all below the $-2.0 \mathrm{BMI}$ zscore cut-point) and dysphagia (1 patient positioned gastrostomy) (Fig. 3). More in detail, ten patients died because of cardiac failure (age: 17, LVEF: 22.8, and FVC\% pred: $42 \%$ ), three of whom had also severe dysphagia, whereas respiratory failure was the main cause of death in four patients (age 21, LVEF: 62.5 and FVC\% pred: 24\%), three of whom showing also important swallowing impairment. Two patients (age 23.5, LVEF: 27.5 and FVC\% pred: $23 \%$ ) died because of combined reasons, cardiac, respiratory and nutritional failure.

Regular use of CAD and MNIV respectively started at the age of 20 and 19 years, while cardioprotective therapy at the age of 14 years.

\section{Indexes}

For scoliosis, cardiac and respiratory functions and nutrition, Fig. 4 showed the corresponding computed index that included the different items in the alive patients. The median ambulation score was 0 until the age of 9 years and then it became 1 thereafter. The severity of cardiac dysfunction, respiratory dysfunction and nutritional problems became significantly higher since 18 years, while the severity of scoliosis since 13. The global index that comprised all the aforementioned functions was also reported, and its severity started to be significantly higher since the age of 13 years (Fig. 4).

In patients older than 18 years, the index of the cardiac function was limited to a severity value of 0.37 , whereas the other indexes progressively approached 1 , being the maximal level of severity (scoliosis score $=0.75$, nutritional condition score $=0.75$ and respiratory function score $=1$ ), resulting in a global index of 0.75 . The cardiac function in the abovementioned patients, therefore, seemed to be less severely compromised. This was further confirmed when comparing alive and dead peers (Fig. 5, upper panels), the latter were characterized by significantly worse cardiac dysfunction (severity level of 0.70 ) with a similar level (score $=1$ ) of respiratory impairment. Also in patients aged 13-18, the respiratory function was similar between alive $($ score $=0.33)$ and dead (score $=0.33$ ) patients, while the heart function was severely compromised in the latter (score $=0.70$ ) compared to the former (score $=0.17$ ).

The severity of nutritional condition was worse in dead patients (score older patients $=0.69$; score younger patients: 0.50 ) compared to the alive peers ( score older patients $=0.38$; score younger patients: $0.20)$.

All the considered functions, except ambulation, showed a significantly less severe condition (scores) in patients currently treated with steroids compared to naïve and past patients (Fig. 5, middle panels), while site of mutation did not seem to play a role in clinical evolution (Fig. 5, lower panels).

The computation of the scoring system for four representative patients is presented in Table 2 . 


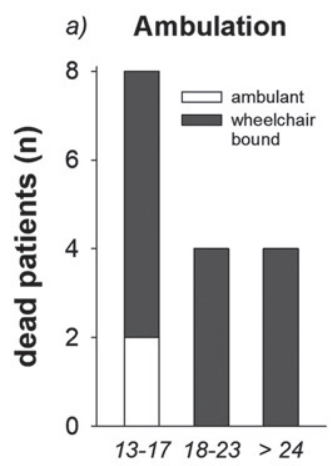

b) Steroid therapy

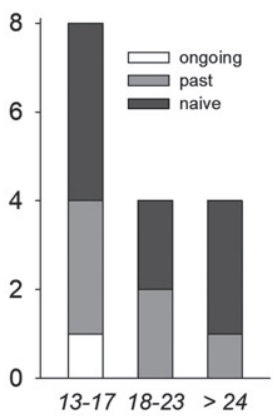

c) Range of scoliosis

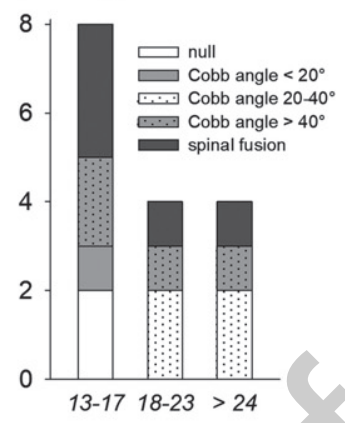

d) LVEF

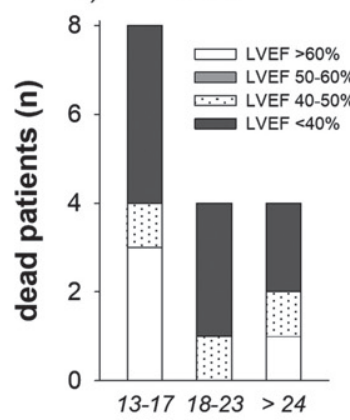

FVC

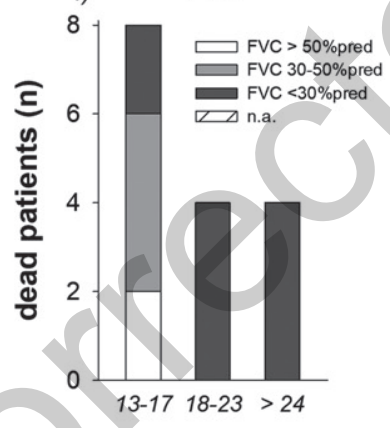

h) Nutritional status

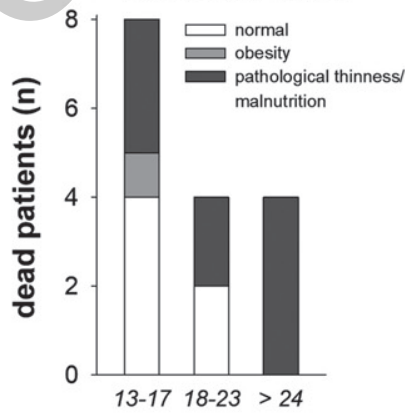

age range (years) e) Arrhythmia

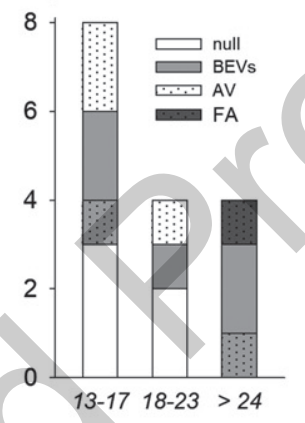

g) Respiratory device

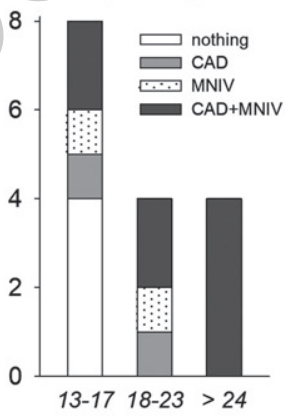

i) Swallowing

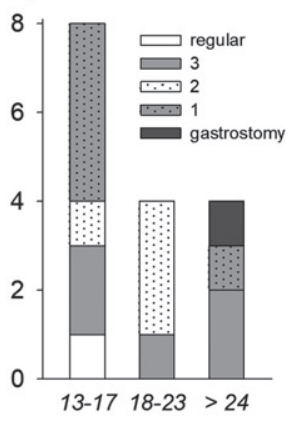

age range (years)

Fig. 3. Stacked diagrams of the different levels of ambulation, steroid therapy, range of scoliosis, left ventricular ejection fraction (LVEF), arrhythmia, forced vital capacity (FVC), respiratory device use, nutritional condition and swallowing disturbances in the dead patients. Data are expressed as the numerosity of each group of age. AV: Ventricular Arrythmias; BEVs: SovraVentricular Extrasistolia; AF: Atrial flutter/Fibrillation; CAD: cough assisted device; MNIV: mechanical non-invasive ventilation. 

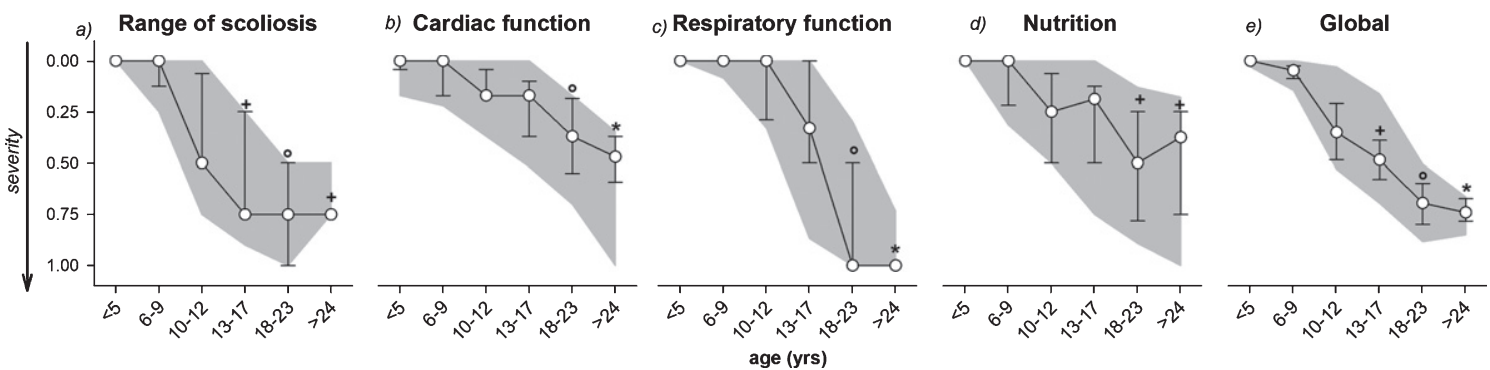

Fig. 4. Evolution with age of the median values of the index computed for each considered item: range of scoliosis, cardiac function, respiratory function, nutritional and swallowing condition (Nutrition) and their mean value (Global) in all the alive DMD patients. Error bars: $25^{\text {th }}$ and $75^{\text {th }}$ percentiles. Grey areas: $10^{\text {th }}$ and $90^{\text {th }}$ percentiles. $+: p<0.05$ vs age $<10$ years; ${ }^{\circ}: p<0.05 v s$ age $<13$ years; ${ }^{*}: p<0.05$ $v s$ age $<18$ years.

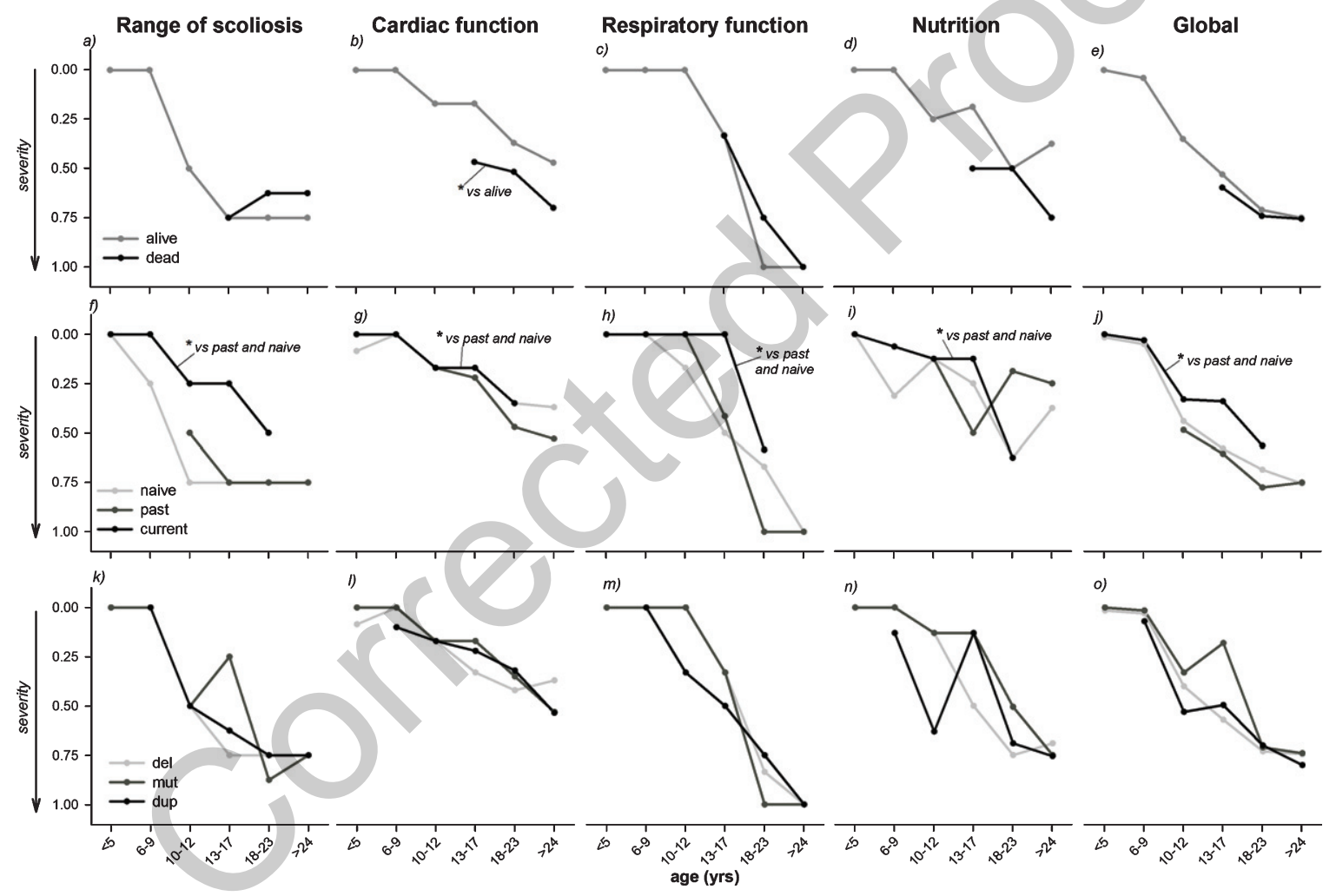

Fig. 5. Evolution with age of the median values of the index computed for each considered item: range of scoliosis, cardiac function, respiratory function, nutritional and swallowing condition (Nutrition) and their mean value (Global) in the alive and dead DMD patients (top panels), according to the use of steroid (middle panels; naive: patients never treated or treated for $<1$ year with steroids, past: patients not under treatment, but previously treated for $>1$ year, current: patients under treatment or stopped since $<1$ year before the visit) and the genetic analysis (bottom panels; del: deletion, mut: point mutation, dup: duplication). ${ }^{*}: p<0.05$.

\section{DISCUSSION}

This study provided a comprehensive multidimensional description of a group of 132 DMD boys including: genotype, steroid therapy, ambulation, scoliosis and spinal fusion, cardiac and respiratory function, nutritional conditionand swallowing. It could be also considered a pilot for a new tool to evaluate multi-systemic clinical outcomes in DMD, as it proposed new score indexes, directly obtained from clinical charts, that allowed to pool together in a graded scale several clinical issues and functional 
Table 2

Scoring system: criteria to compute the functions' scores in 4 representative patients

\begin{tabular}{|c|c|c|c|c|c|c|c|c|c|c|c|c|c|c|c|c|c|}
\hline \multirow[b]{2}{*}{ Function } & \multirow[b]{2}{*}{ item } & \multicolumn{4}{|c|}{ patient A: age 15 yrs, alive } & \multicolumn{4}{|c|}{ patient $B$ : age 13 yrs, dead } & \multicolumn{4}{|c|}{ patient $C$ : age 25 yrs, alive } & \multicolumn{4}{|c|}{ patient D: age 24 yrs, dead } \\
\hline & & value & score & N_score & $\begin{array}{l}\text { function } \\
\text { score }\end{array}$ & value & score & N_score & $\begin{array}{l}\text { function } \\
\text { score }\end{array}$ & value & score & N_score & $\begin{array}{l}\text { function } \\
\text { score }\end{array}$ & value & score & N_score & $\begin{array}{l}\text { function } \\
\text { score }\end{array}$ \\
\hline Ambulation & Wheelchair & no & 0 & 0 & 0 & yes & 1 & 1 & 1 & yes & 1 & 1 & 1 & yes & 1 & 1 & 1 \\
\hline Scoliosis & Cobb-angle & $25^{\circ}$ & 1 & 0.25 & 0.25 & $0^{\mathrm{o}}$ & 0 & 0 & $\mathbf{0}$ & $45^{\circ}$ & 3 & 0.75 & 0.75 & $30^{\circ}$ & 2 & 0.5 & 0.50 \\
\hline \multirow[t]{2}{*}{ Cardiac } & LVEF & $58 \%$ & 1 & 0.33 & 0.17 & $22 \%$ & 3 & 1 & 0.70 & $55.5 \%$ & 1 & 0.33 & 0.17 & $23 \%$ & 3 & 1 & 0.70 \\
\hline & Cardiac rhythm & no & 0 & 0 & & SVE & 2 & 0.4 & & no & 0 & 0 & & SVE & 2 & 0.4 & \\
\hline \multirow[t]{3}{*}{ Respiratory } & FVC & $76 \%$ & 0 & 0 & 0.33 & $66 \%$ & 0 & 0 & $\mathbf{0}$ & $40 \%$ & 1 & 0.5 & 0.83 & $19 \%$ & 2 & 1 & 1.0 \\
\hline & CAD & yes & 1 & 1 & & no & 0 & 0 & & yes & 1 & 1 & & yes & 1 & 1 & \\
\hline & MNIV & no & 0 & 0 & & no & 0 & 0 & & yes & 1 & 1 & & yes & 1 & 1 & \\
\hline \multirow[t]{2}{*}{$\begin{array}{l}\text { Gastrointestinal } \\
\text { and nutritional }\end{array}$} & $\begin{array}{l}\text { Nutritional } \\
\text { status }\end{array}$ & normal & 0 & 0 & 0.13 & normal & 0 & & 0.25 & $\begin{array}{l}\text { pathological } \\
\text { thinness }\end{array}$ & 1 & 1 & 0.75 & normal & 0 & 0 & 0.13 \\
\hline & Swallowing & $\begin{array}{c}\text { mild } \\
\text { dysphagia }\end{array}$ & 1 & 0.25 & & $\begin{array}{l}\text { moderate } \\
\text { dysphagia }\end{array}$ & 0 & 05 & & $\begin{array}{l}\text { moderate } \\
\text { dysphagia }\end{array}$ & 2 & 0.5 & & $\begin{array}{c}\text { Mild } \\
\text { dysphagia }\end{array}$ & 1 & 0.25 & \\
\hline Global & & & & & 0.18 & & & & 0.39 & & & & 0.7 & & & & 0.67 \\
\hline
\end{tabular}

The value of each item is firstly converted into the corresponding score and then normalized (N-score), according to Table 1. If the function is composed by only one item, its score corresponds to the N_score of the item, otherwise it is calculated as the mean of the N-scores of all its items (cardiac function: mean of LVEF and Cardiac rhythm; respiratory function: mean of FVC\%pred, $\mathrm{CAD}$ and MNIV; gastrointestinal and nutritional function: mean of nutritional condition and swallowing). Finally, the global score is computed as the mean of the scores of all the 5 functions (ambulation, scoliosis, cardiac, respiratory, gastrointestinal and nutritional function). In the table, we can observe the role of cardiac dysfunction in patients' survival. The global score was similar between the two older patients; however, it was the result of two different distribution of functions' severity. Respiratory function was severely compromised in both patients, severe cardiac dysfunction was present only in the dead patient, while nutritional dysfunction only in the alive one. The global score was lower in the two younger boys, with the cardiac function playing the major role in the dead one. 
parameters despite their heterogeneity. A single global score that combined the 4 scores was also calculated.

\section{Multisystemic clinical impairment in DMD: Incidence}

With the increasing expectation of life, DMD patients experience several additional disease complications requiring a multi-systemic approach. Wong et al firstly studied long term outcome of interdisciplinary management of patients with DMD receiveing steroids in 2002. They considered scoliosis, motor, pulmonary and cardiac functions as outcome measures, while growth, weight, bone health, gastrointestinal symptoms were considered only as steroid side effects [9]. In a recent report clinical data from 5345 DMD boys from 31 countries, the effects of corticosteroid treatment on ambulation, need for scoliosis surgery, ventilation and, to a lesser extent, cardiomyopathy were cathegorized and stratified by age. These data were obtained by patients registries database [8]. These two studies, however, were mainly focused on the multi-systemic effects of steroid with age. Conversely, the present study considered several clinical issues and functional parameters, directly obtained from clinical charts, and described the progression of the disease in a wide age range (3.5-32.3 years) of DMD population.

In our cohort of patients, loss of ambulation occured at the median age of 10 . In accordance with the literature [27], it was associated with progressive scoliosis in more than $70 \%$ of the patients since the age of 13 . Only 14 patients underwent spinal fusion, the majority of whom was aged 18-24 at time of the study. This suggested a more conservative surgical attitude in recent years together with the hereby documented efficacy on prevention of spine deformity of steroid therapy [7].

In the alive patients, cardiac abnormalities became evident in a quarter of patients older than 18 years, as already shown by Nigro et al. [28]. All the alive patients took advantages from early treatment with beta blockers and Angiotensin Converting Enzyme inhibitors and, when needed since 2015, from the implant of automatic cardioverter-defibrillators [26].

On the other hand, severe and rapidly progressive left ventricle dysfunction and arrythmias were present in most of $(75 \%)$ dead patients at any age, despite pharmacological treatment with beta blockers, Angiotensin Converting Enzyme inhibitors, diuretics and digoxin [26]. Their death mainly occurred at the beginning of 2010s at a median age of 19 years. This might presumably explain the different cardiac severity found in the cardiac scoring system between alive and dead patients. Early pharmacological treatment and the implant of automatic cardioverter-defibrillators [26], therefore, seemed to play a protective role in natural cardiac history even in our relatively small population.

Spirometric data were not available in patients younger than 5 , because of their inability to perform a reliable test, and in the $20 \%$ of patients older than 18 years for the physical problems derived from the progression of the dystrophy. As expected, after an initial increment from 6 to 12 years, FVC\% $\%$ pred declined thereafter [29, 30].

Cough inefficiency became evident since early stages of the disease. After the age of 9 years, the percentage of patients regularly using CAD was already $20 \%$. The compliance to this medical indication in all the oldest patients was excellent $(100 \%)$.

There were 4 years of delay in the use of CAD between alive (16 years) and deceased (20 years) patients that may have contributed to worsen the respiratory function of the latter.

In the age group 13-17 years, only the 13\% of patients who met the clinical guidelines indications to start MNIV [7, 13] immediately accepted its regular use. The number of patients under MNIV increased with age, showing good adherence to ATS guidelines [13]. Although the compliance of MNIV never reached $100 \%$ as with CAD, it was significantly higher in our patients than that reported in the study from the TREAT-NMD DMD Global Database [8]. To our opinion, also the financial support for therapies, devices and hospitalization of the Italian National Health Service seemed to play a relevant role. It is important to underline that we have reported the effective use of MNIV and not the age at which patients met the indications to start it. It happened, in fact, that some (few) patients/families refused this indication for different reasons like acceptance of clinical worsening and/or depression.

In our population, moreover, the use of steroids, MNIV and CAD allowed a reduction of the number of airways infection leading to acute respiratory insufficiency as also indicated by the lack of tracheostomized patients.

An originality of the present study was considering also the nutritional condition, not only in terms of obesity, as a side effect of steroid therapy and wheelchair bounding [31], but also in terms of reduction of nutrient support due to swallowing 
disturbances. Obesity was observed mainly between 10 and 17 years. Pathological thinness and malnutrition coincided with the beginning of swallowing disturbances that may start since relatively early stages of the disease. This might be related to weakness of the muscles involved in the oropharyngeal phase of swallowing, causing either weight loss or aspiration pneumonia. Underweight together with respiratory decline are considered poor prognostic factors in DMD [32]. This was confirmed also in our small cohort of patients; as severe nutritional problems were present in 9 out of the 16 dead patients.

Of note, the use of the BMI classification applied for the general population may not be optimal for patients with DMD. In the US, DMD patients were shown to be shorter and to tend to the extremes of weight and BMI compared with the general male paediatric population [33]. Considering the prolonged survival of DMD patients and the consequent additional nutritional complications to be handled, the lack of growth curves for European DMD population for all ages represents an important limitation. Body composition changes during the course of the disease because of reduced mobility, steroid treatment, decreased lean body mass [34, 35]. For this reason, longitudinal growth charts specific for DMD would be extremely important to monitor the clinical appraisal of growth and nutrition condition.

\section{Multisystemic clinical impairment in DMD: The scoring system}

The analysis conducted so far focused on the evolution of every single parameter representing only a single aspect of the function. Conversely, the introduction of the proposed index allowed each function to be described by taking into account different and heterogeneous functional items. In this way, the attention was focused on the overall function including the different aspects that characterized it.

Based on of our results, cardiac function, respiratory function and nutrition seemed to significantly decline since the age of 18 , while scoliosis seemed to worsen earlier, i.e. at the age of 13 . While genetics (namely, site of mutation in the DMD gene) did not seem to play a role among the three considered groups, steroid therapy did have a relevant impact on the evolution of DMD.

Most of the oldest patients ( $>24$ years) were never treated with steroids ("naïve"). They were born between 1980 and 1990's, long time before the knowledge of the documented benefits deriving from steroid therapy. On the other hand, almost all boys aged 6-9 years were currently under steroid treatment, that was maintained also after loss of ambulation until the occurrence of side effects, underlying a good compliance to standard of care guidelines published in 2004-2005 [36, 37].

In accordance to data reported in literature [8, 38], naive patients lost ambulation at the median age of 10 years. Suprisingly, in our study, current and past treated patients lost ambulation at a similar age. Steroid therefore did not seem to prolong ambulation although few treated patients were still ambulant after 16 years. On the other hand, steroids positively affected all the considered functions (spine, heart, breath, nutrition and global) at all ages. The index scores, in fact, indicated that currently treated patients presented a statistically significant less severe involvement in the range of scoliosis, cardiac and respiratory function, nutrition and in the global final index.

Steroids are supposed to play a protective role on cardiac function [31, 39], and this was relatively true in our study too, as almost all the dead patients were not under treatment.

Cardiac function was the only index showing a statistically significant difference when dead patients were compared to alive DMD peers (older than 12 years), suggesting a stronger role of heart dysfunction in DMD decease than other parameters. Early cardiac dysfunction, therefore, seemed to be related to reduced life expectancy; while for the alive patients a good compliance to respiratory care management played a role in survival [40].

One third of our population followed by a multidisciplinary team with prompt treatments of cardiac, pulmonary and nutrional complications according to the standard of care guidelines [7, 10-12,41], was older than 18 years with a relatively good quality of life, as previously shown [42-45]. Although both the respiratory and the nutritional functions were severely compromised in these patients (score 1 and 0.75 , respectively), it seemed that their prompt care contributed to the global physical wellbeing and prolonged survival, as long as their cardiac function was less compromised (0.37) and responsive to pharmacological treatment.

\section{Strengths and limitations}

Our approach had several strengths: 1) different aspects of the natural history of the disease were considered in a large number of patients; 2) data were 
collected from clinical sheets by medical staff and not from databases; and 3) the introduction of a new grading score able to integrate different and heterogeneous parameters that allowed describing a specific function in its different aspects.

The indexes were easy-to-obtained from clinical charts without requiring difficult computation and therefore they could be exported/proposed also outside our Italian tertiary care center. All the thresholds considered to rank the severity of each function/parameter were based on clinical guidelines.

The second main purpose of this study was to understand the feasibility of putting together heterogeneous functions, parameters and items and summarizing them into a number, to be used in a larger scale study. This was an interesting pilot study that proposes a promising system-score as new clinical tool. It had a lot of potential useful applications: 1) benchmarking to evaluate the effect in treatment protocols within a single centre or multicentre on a national or international level; 2) evaluation of drug effects other than systemic corticosteroid; 3) individual indicator for prognosis and timing for intervention; 4) stratifying patients and then correlating each class of scoring stratification with the likelihood of occurrence of different clinically meaningful events/outcomes, 5) merging different co-morbidities of DMD; 6) identification of possible clinical subgroups of patients according to the progression of the indexes; 7) use of these identified subgroups to optimize inclusion criteria in clinical trials and 8) survival analysis. However, this promising and innovative approach to process and report patient data needed future research. Being a single centre experience was a weakness and the number of dead patients was too small to generalise results. The low number of deceased patients was the main reason why the same weight was attributed to all the items composing the function, and to all the functions in the global index. This was the main bottleneck of the scoring system, that might be fixed by extending to a multicentre study on bigger databases focused to compute the relative clinical impact of each parameter, item and function not only to survival but also to quality of life. The solution to this optimization problem would therefore set the optimal values of the weight of each variables, so that global index could become an individual prognostic indicator. In addition, the proposed tool could also include additional functions and items like nocturnal oxygen desaturation, activities of daily living and psychosocial indicators (quality of life, mental health, participation) so that correlation with functional and emotional conditions and changed scores of patients could be possible. Another potential future improvement might be represented by a more detailed definition of clinical levels of some items, for example: 1) adding a further lower level for LVEF, in order to better monitor severe cardiac dysfunction; 2) assigning MNIV scores by hours of use, in order to better monitor severe respiratory dysfunction.

However, the trend of all the indexes follows the pathophysiology of DMD and this is an encouraging result of the validity of the system.

To conclude, with more widespread prolonged survival, DMD patients require a multidisciplinary approach to guarantee care of multifactorial complications resulting in good quality of life [11]. We provided a comprehensive description of the clinical condition of quite a wide number of DMD patients, considering different aspects of the disease: genotype, steroid therapy, ambulation, scoliosis, spinal fusion, cardiac and respiratory function, nutritional condition and swallowing. We have also demonstrated the possibility to aggregate and correlate these different parameters, items and functions despite their heterogeneity. The proposed indexes were easyto-obtaine from any clinical chart and had the potentiality of allowing multicentre studies in order to optimize the management of both the primary and the secondary complications of DMD and to understand their relative impact.

\section{ACKNOWLEDGMENTS}

The authors thank all patients and families for their collaboration and the medical personnel of the IRCCS "E. Medea" involved in the care and evaluation of the patients (E. Marchi, D.Colombo, P.Scarpazza, M. Grandi, V.Landoni, L.Gavazzi, V. Maiocchi, C.Rosci, C.Legnani, E.Diella, F.Civati, E.Mornati, A. Negri).

This paper is dedicated to the loving memory of Antonio D'Angelo.

\section{FUNDING}

This work has been supported by the National Ministery of Health (Ricerca Finalizzata 2009 - RF 2009-1473897 and Ricerca Corrente 2011-2014) and by Fondo DMD Amici di Emanuele Onlus. 


\section{REFERENCES}

[1] Ciafaloni E, Kumar A, Liu K, Pandya S, Westfield C, Fox DJ, et al. Age at onset of first signs or symptoms predicts age at loss of ambulation in Duchenne and Becker Muscular Dystrophy: Data from the MD STARnet. J Pediatr Rehabil Med. 2016;9:5-11. doi:10.3233/PRM-160361

[2] D'Amico A, Catteruccia M, Baranello G, Politano L, Govoni A, Previtali SC, et al. Diagnosis of Duchenne Muscular Dystrophy in Italy in the last decade: Critical issues and areas for improvements. Neuromuscul Disord. 2017;27:447-51. doi:10.1016/j.nmd.2017.02.006

[3] Ishikawa Y, Miura T, Ishikawa Y, Aoyagi T, Ogata H, Hamada S, et al. Duchenne muscular dystrophy: Survival by cardio-respiratory interventions. Neuromuscul Disord. 2011;21:47-51. doi:10.1016/j.nmd.2010.09.006

[4] Bach JR, Martinez D. Duchenne muscular dystrophy: Continuous noninvasive ventilatory support prolongs survival. Respir Care. 2011;56:744-50. doi:10.4187/respcare. 00831

[5] Gomez-Merino E, Bach JR. Duchenne muscular dystrophy: Prolongation of life by noninvasive ventilation and mechanically assisted coughing. Am J Phys Med Rehabil. 2002;81:411-5.

[6] Duboc D, Meune C, Pierre B, Wahbi K, Eymard B, Toutain $A$, et al. Perindopril preventive treatment on mortality in Duchenne muscular dystrophy: 10 years' follow-up. Am Heart J. 2007;154:596-602. doi:10.1016/j.ahj.2007. 05.014

[7] Birnkrant DJ, Bushby K, Bann CM, Alman BA, Apkon SD, Blackwell A, et al. Diagnosis and management of Duchenne muscular dystrophy, part 2: Respiratory, cardiac, bone health, and orthopaedic management. Lancet Neurol. 2018;17:347-61. doi:10.1016/S1474-4422(18)30025-5

[8] Koeks Z, Bladen CL, Salgado D, van Zwet E, Pogoryelova $\mathrm{O}$, McMacken $\mathrm{G}$, et al. Clinical Outcomes in Duchenne Muscular Dystrophy: A Study of 5345 Patients from the TREAT-NMD DMD Global Database. J Neuromuscul Dis. 2017;4:293-306. doi:10.3233/JND-170280

[9] Wong BLY, Christopher C. Corticosteroids in Duchenne muscular dystrophy: A reappraisal. J Child Neurol. 2002;17:183-90.

[10] Birnkrant DJ, Bushby K, Bann CM, Apkon SD, Blackwell A, Brumbaugh D, et al. Diagnosis and management of Duchenne muscular dystrophy, part 1: Diagnosis, and neuromuscular, rehabilitation, endocrine, and gastrointestinal and nutritional management. Lancet Neurol. 2018;17:25167. doi:10.1016/S1474-4422(18)30024-3

[11] Birnkrant DJ, Bushby K, Bann CM, Apkon SD, Blackwell A, Colvin MK, et al. Diagnosis and management of Duchenne muscular dystrophy, part 3: Primary care, emergency management, psychosocial care, and transitions of care across the lifespan. Lancet Neurol. 2018;17:445-55. doi:10.1016/S1474-4422(18)30026-7

[12] Bushby K, Finkel R, Birnkrant DJ, Case LE, Clemens PR, Cripe L, et al. Diagnosis and management of Duchenne muscular dystrophy, part 1: Diagnosis, and pharmacological and psychosocial management. Lancet Neurol. 2010;9:77-93. doi:10.1016/S1474-4422(09)70271-6

[13] Finder JD, Birnkrant D, Carl J, Farber HJ, Gozal D, Iannaccone ST, et al. Respiratory care of the patient with Duchenne muscular dystrophy: ATS consensus statement. Am J Respir Crit Care Med. 2004;170:456-65. doi:10.1164/rccm.200307-885ST
[14] Lo Mauro a., D’Angelo MG, Romei M, Motta F, Colombo D, Comi GP, et al. Abdominal volume contribution to tidal volume as an early indicator of respiratory impairment in Duchenne muscular dystrophy. Eur Respir J. 2010;35:111825. doi:10.1183/09031936.00037209

[15] Kamdar F, Garry DJ. Dystrophin-Deficient Cardiomyopathy. J Am Coll Cardiol. 2016;67:2533-46. doi: 10.1016/j.jacc.2016.02.081

[16] Villa CR, Czosek RJ, Ahmed H, Khoury PR, Anderson JB, Knilans TK, et al. Ambulatory Monitoring and Arrhythmic Outcomes in Pediatric and Adolescent Patients With Duchenne Muscular Dystrophy. J Am Heart Assoc. 2016;5:e002620. doi:10.1161/JAHA.115.002620

[17] Mayer OH, Leinonen M, Rummey C, Meier T, Buyse GM, DELOS Study Group. Efficacy of Idebenone to Preserve Respiratory Function above Clinically Meaningful Thresholds for Forced Vital Capacity (FVC) in Patients with Duchenne Muscular Dystrophy. J Neuromuscul Dis. 2017;4:189-98. doi:10.3233/JND-170245

[18] West NA, Yang ML, Weitzenkamp DA, Andrews J, Meaney FJ, Oleszek J, et al. Patterns of Growth in Ambulatory Males with Duchenne Muscular Dystrophy. J Pediatr. 2013;163:1759-1763.e1. doi:10.1016/j.jpeds.2013. 08.004

[19] Sarrazin E, von der Hagen M, Schara U, von Au K, Kaindl AM. Growth and psychomotor development of patients with Duchenne muscular dystrophy. Eur J Paediatr Neurol. 2014;18:38-44. doi:10.1016/j.ejpn.2013.08.008

[20] World Health Organization. Obesity: Preventing and managing the global epidemic. Report of a WHO Consultation (WHO Technical Report Series 894), n.d.

[21] Kuczmarski RJ, Ogden CL, Guo SS, Grummer-Strawn LM, Flegal KM, Mei Z, et al. 2000 CDC growth charts for the United States: Methods and development. Vital Heal Stat Ser 11 Data from Natl Heal Surv Natl Heal Nutr Exam Surv Hisp Heal Nutr Exam Surv. 2002;11.

[22] Tilton AH, Miller MD, Khoshoo V. Nutrition and swallowing in pediatric neuromuscular patients. Semin Pediatr Neurol. 1998;5:106-15.

[23] Toussaint M, Davidson Z, Bouvoie V, Evenepoel N, Haan J, Soudon P. Dysphagia in Duchenne muscular dystrophy: Practical recommendations to guide management. Disabil Rehabil. 2016;38:2052-62. doi:10.3109/ 09638288.2015.1111434

[24] Pane M, Vasta I, Messina S, Sorleti D, Aloysius A, Sciarra $\mathrm{F}$, et al. Feeding problems and weight gain in Duchenne muscular dystrophy. Eur J Paediatr Neurol. 2006;10:231-6. doi:10.1016/j.ejpn.2006.08.008

[25] van den Engel-Hoek L, de Groot IJM, de Swart BJM, Erasmus CE. Feeding and Swallowing Disorders in Pediatric Neuromuscular Diseases: An Overview. J Neuromuscul Dis. 2015;2:357-69. doi:10.3233/JND-150122

[26] Yancy CW, Jessup M, Bozkurt B, Butler J, Casey DE, Drazner MH, et al. 2013 ACCF/AHA Guideline for the Management of Heart Failure. J Am Coll Cardiol. 2013;62:e147-239. doi:10.1016/j.jacc.2013.05.019

[27] Biggar WD, Harris VA, Eliasoph L, Alman B. Long-term benefits of deflazacort treatment for boys with Duchenne muscular dystrophy in their second decade. Neuromuscul Disord. 2006;16:249-55. doi:10.1016/j.nmd.2006.01.010

[28] Nigro G, Comi LI, Politano L, Bain RJ. The incidence and evolution of cardiomyopathy in Duchenne muscular dystrophy. Int J Cardiol. 1990;26:271-7.

[29] LoMauro A, Romei M, Gandossini S, Pascuzzo R, Vantini S, D'Angelo MG, et al. Evolution of respiratory 
function in Duchenne muscular dystrophy from childhood to adulthood. Eur Respir J. 2018;51:1701418. doi:10.1183/13993003.01418-2017

[30] Mayer OH, Finkel RS, Rummey C, Benton MJ, Glanzman a. M, Flickinger J, et al. Characterization of pulmonary function in Duchenne Muscular Dystrophy. Pediatr Pulmonol. 2015;50:487-94. doi:10.1002/ppul.23172

[31] Matthews E, Brassington R, Kuntzer T, Jichi F, Manzur AY. Corticosteroids for the treatment of Duchenne muscular dystrophy. Cochrane Database Syst Rev. 2016:CD003725. doi:10.1002/14651858.CD003725.pub4

[32] Cheeran D, Khan S, Khera R, Bhatt A, Garg S, Grodin JL, et al. Predictors of Death in Adults With Duchenne Muscular Dystrophy-Associated Cardiomyopathy. J Am Heart Assoc. 2017;6:e06340. doi:10.1161/JAHA.117.006340

[33] West NA, Yang ML, Weitzenkamp DA, Andrews J, Meaney FJ, Oleszek J, et al. Patterns of growth in ambulatory males with duchenne muscular dystrophy. J Pediatr. 2013;163. doi:10.1016/j.jpeds.2013.08.004

[34] McDonald CM, Carter GT, Abresch RT, Widman L, Styne DM, Warden N, et al. Body composition and water compartment measurements in boys with Duchenne muscular dystrophy. Am J Phys Med Rehabil. 2005;84:483-91. doi:10.1097/01.phm.0000166880.91117.04

[35] Willig T-N, Carlier L, Legrand M, Rivière H, Navarro J. Nutritional assessment in duchenne muscular dystrophy. Dev Med Child Neurol. 1993;35:1074-82. doi:10.1111/j.1469-8749.1993.tb07925.x

[36] Moxley RT, Ashwal S, Pandya S, Connolly A, Florence J, Mathews K, et al. Practice parameter: Corticosteroid treatment of Duchenne dystrophy: Report of the Quality Standards Subcommittee of the American Academy of Neurology and the Practice Committee of the Child Neurology Society. Neurology. 2005;64:13-20. doi:10.1212/01.WNL.0000148485.00049.B7

[37] Bushby K, Muntoni F, Urtizberea A, Hughes R, Griggs R. Report on the 124th ENMC International Workshop. Treatment of Duchenne muscular dystrophy; defining the gold standards of management in the use of corticosteroids. 2-4 April 2004, Naarden, The Netherlands. Neuromuscul Disord. 2004;14:526-34. doi:10.1016/j.nmd.2004.05.006
[38] Wong BL, Rybalsky I, Shellenbarger KC, Tian C, McMahon MA, Rutter MM, et al. Long-Term Outcome of Interdisciplinary Management of Patients with Duchenne Muscular Dystrophy Receiving Daily Glucocorticoid Treatment. J Pediatr. 2017;182:296-303.e1. doi:10.1016/j.jpeds.2016.11.078

[39] Schram G, Fournier A, Leduc H, Dahdah N, Therien J, Vanasse M, et al. All-Cause Mortality and Cardiovascular Outcomes With Prophylactic Steroid Therapy in Duchenne Muscular Dystrophy. J Am Coll Cardiol. 2013;61:948-54. doi:10.1016/j.jacc.2012.12.008

[40] Van Ruiten HJA, Marini Bettolo C, Cheetham T, Eagle M, Lochmuller H, Straub V, et al. Why are some patients with Duchenne muscular dystrophy dying young: An analysis of causes of death in North East England. Eur J Paediatr Neurol. 2016;20:904-9. doi:10.1016/j.ejpn.2016.07.020

[41] Bushby K, Finkel R, Birnkrant DJ, Case LE, Clemens PR, Cripe L, et al. Diagnosis and management of Duchenne muscular dystrophy, part 2: Implementation of multidisciplinary care. Lancet Neurol. 2010;9:177-89. doi:10.1016/S14744422(09)70272-8

[42] Messina S, Vita GL, Sframeli M, Mondello S, Mazzone E, D'Amico A, et al. Health-related quality of life and functional changes in DMD: A 12-month longitudinal cohort study. Neuromuscul Disord. 2016;26:189-96. doi:10.1016/j.nmd.2016.01.003

[43] Politano L, Scutifero M, Patalano M, Sagliocchi A, Zaccaro A, Civati F, et al. Integrated care of muscular dystrophies in Italy. Part 1. Pharmacological treatment and rehabilitative interventions. Acta Myol Myopathies Cardiomyopathies Off J Mediterr Soc Myol. 2017;36:19-24.

[44] Magliano L, Scutifero M, Patalano M, Sagliocchi A, Zaccaro A, Civati F, et al. Integrated care of muscular dystrophies in Italy. Part 2. Psychological treatments, social and welfare support, and financial costs. Acta Myol Myopathies Cardiomyopathies Off J Mediterr Soc Myol. 2017;36:41-5.

[45] Magliano L, Patalano M, Sagliocchi A, Scutifero M, Zaccaro A, D' Angelo MG, et al. "I have got something positive out of this situation": Psychological benefits of caregiving in relatives of young people with muscular dystrophy. J Neurol. 2014;261:188-95. doi:10.1007/s00415-013-7176-8

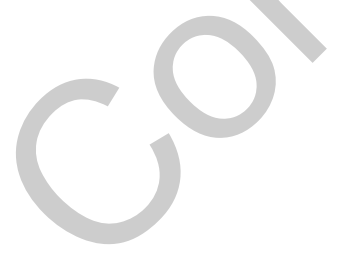

